Please visit the Heart website (www.heartjnl.com) for links to these articles-many to full text.

\section{ISCHAEMIC HEART DISEASE}

The panel decides that the UK under uses revascularisation ... and this is bad for the patient: A panel of cardiologists, surgeons, epidemiologists, and others considered the evidence for revascularisation in multiple clinical scenarios. They then assessed clinical outcome based on whether the strategy that the panel would have chosen was applied retrospectively in a group of over 2500 patients undergoing angiography. They showed that revascularisation was underused, and that if the panel's decision was not followed, then the patients had more angina but also higher mortality.

1 Hemingway H, Crook AM, Feder G, Banerjee S, Dawson JR, Magee P, Philpott S, Sanders J, Wood A, Timmis AD. Underuse of coronary revascularization procedures in patients considered appropriate candidates for revascularization. N Engl J Med 2001;344:645-54.

Your genes decide if moderate alcohol intake is really good for you: A polymorphism in the gene for alcohol dehydrogenase type $3(\mathrm{ADH} 3)$ alters the rate of alcohol metabolism. Moderate drinkers who are homozygous for the slow oxidizing $\mathrm{ADH} 3$ allele have higher high density lipoprotein (HDL) concentrations and a substantially decreased risk of myocardial infarction.

2 Hines LM, Stampfer MJ, Ma J, Gaziano JM, Ridker PM, Hankinson SE, Sacks F, Rimm EB, Hunter DJ. Genetic variation in alcohol dehydrogenase and the beneficial effect of moderate alcohol consumption on myocardial infarction. N Engl J Med 2001;344:549-55.

Non-invasive coronary angiography with CT scanning: Multi-slice computed tomography (CT) of coronary arteries was compared to conventional angiography in a range of coronary disorders. There were some problems in this small preliminary study - for example, with calcifications and stents - but 17 of 21 significant stenoses were identified correctly. Anomalous coronary anatomy could be visualised well. This technique might be easier to disseminate in the UK than cardiac magnetic resonance imaging, which is available only to the lucky few.

3 Nieman K, Oudkerk M, Rensing BJ, van Ooijen P, Munne A, van Geuns R-J, de Feyter PJ. Coronary angiography with multi-slice computed tomography. Lancet 2001;357:599-603.

Aspirin and ACE inhibitors are safe to use together: Major trials show that aspirin and angiotensin converting enzyme (ACE) inhibitors reduce mortality post myocardial infarction (MI). Some people worry that aspirin negates the beneficial effects of ACE inhibitors. This study of elderly survivors of MI showed that $16 \%$ received neither drug, $38 \%$ received both, and about $25 \%$ received either one or the other. The majority of patients were, therefore, on at least some treatment. There was no reduction in the benefits by combining therapy, with a trend towards combined treatment being advantageous.

4 Krumholz HM, Chen Y-T, Wang Y, Radford MJ. Aspirin and angiotensinconverting enzyme inhibitors among elderly survivors of hospitalization for an acute myocardial infarction. Arch Intern Med 2001;161:538-44.

\section{HYPERTENSION}

Angiotensin receptor blocker (AARBs) plus ACE inhibitor reduces blood pressure effectively, but does it do anything else?: The CALM study recruited diabetics with hypertension and microalbuminuria for a comparison of candesartan, lisinopril or both. Each of these agents reduced blood pressure by about $15 / 10 \mathrm{~mm} \mathrm{Hg}$, but the combination achieved a reduction of $25 / 16 \mathrm{~mm} \mathrm{Hg}$ safely. However, addition of the AARB did not reduce microalbuminuria further than the ACE inhibitor alone.
1 Morgensen CE, Neldam S, Tikkanen I, Oren S, Viskoper R, Watts RW, Cooper ME. Randomised controlled trial of dual blockade of renin-angiotensin system in patients with hypertension, and non-insulin dependent diabetes: the candesartan and lisinopril microalbuminuria (CALM) study. BMJ 2000;321:1440-4.

\section{GENERAL CARDIOLOGY}

RBBB is not benign if you are older or have coronary disease: In a study of over 200000 young patients with right (RBBB) and left (LBBB) bundle branch block, RBBB carried no sinister outcome, thus the feeling that RBBB was not as bad as LBBB. However, RBBB gets more prevalent with age and carries a bad prognosis if occurring during the course of an MI. The latest study of referrals with suspected coronary disease to the nuclear cardiology facility for exercise testing, suggests that in the older population (mean age 66 ), mortality at six years is $24 \%$ with RBBB or with $\mathrm{LBBB}$ versus $11 \%$ without BBB. Even after correction for multiple factors the risk of death with RBBB is 1.5 times normal. Partial RBBB does not share this bad prognosis, however.

1 Rotman M, Triebwasser $\mathrm{JH}$. A clinical and follow-up study of right and left bundle branch block. Circulation 1975;51:477-84.

2 Schneider JF, Thomas HE, Sorlie P, Kreger BE, McNamara PM, Kannel WB. Comparative features of newly acquired left and right bundle branch block in the general population: the Framingham study. Am J Cardiol 1981;47:931-40.

3 Hesse B, Diaz LA, Snader CE, Blackstone EH, Lauer MS. Complete bundle branch block as an independent predictor of all-cause mortality: report of 7,073 patients referred for nuclear exercise. Am J Med 2001;110:253-9.

PTCA and CABG provide equal protection from serious adverse events during subsequent non-cardiac surgery: Rates of major adverse cardiac events after successful revascularisation are low, and this trial suggests that whether it is with coronary angioplasty (PTCA) or bypass grafting (CABG) is immaterial. Patients in the BARI trial were at low-medium risk of adverse events if undergoing non-cardiac surgery, and a comparison with a model of predicted risk suggests revascularisation produces a lower than expected risk of events after non-cardiac surgery. Stents, used frequently with PTCA in other situations, should not be used because of the combined risks of bleeding with the concomitant use of aggressive antiplatelet agents and stent thrombosis caused by the hypercoagulable postoperative state.

4 Hassan SA, Hlatky MA, Boothroyd DB, Winston C, Mark DB, Brooks MM, Eagle KA. Outcomes of noncardiac surgery after coronary bypass surgery or coronary angioplasty in the bypass angioplasty revascularization investigation (BARI). Am J Med 2001;110:260-6.

5 Lee TH, Marcantonio ER, Mangione CM, Thomas EJ, Polanczyk CA, Cook F, Sugarbaker DJ, Donaldson MC, Poss R, Ho KKL, Ludwig LE, Pedan A, Goldman L. Derivation and prospective validation of a simple index for prediction of cardiac risk of major noncardiac surgery. Circulation 1999;100:1043-9.

Anorexigen induced valve damage remains stable if you stop the drug: An association between the dietary suppressants fenfluramine and dexfenfluramine and valvar heart disease was first described in 1997. Mast and colleagues performed serial echocardiography on 50 patients who had had previous exposure to the drugs with at least mild mitral or aortic regurgitation. Valvar regurgitation improved or remained stable in most patients after treatment ended. Worsening of valvar regurgitation was uncommon, occurring in two of the 38 patients with mitral regurgitation and two of the 43 patients with aortic regurgitation. Weissman and associates, with one year follow up after stopping the drug, showed reduced aortic regurgitation and no change in mitral regurgitation.

6 Mast ST, Jollis JG, Ryan T, Anstrom KJ, Crary JL. The progression of fenfluramine-associated valvular heart disease assessed by echocardiography. Ann Intern Med 2001;134:261-6.

7 Weissman NJ, Panza JA, Tighe JF, Gwynne JT. Natural history of valvular regurgitation 1 year after discontinuation of dexfenfluramine therapy. Ann Intern Med 2001;134:267-73. 
It is safe to hold off warfarin for two weeks in a patient with a prosthetic valve and a GI bleed, but beware of rebleeding when you restart: This study identified 24 patients with valve prostheses (mitral and/or aortic) receiving warfarin who had been hospitalised for a major haemorrhage. There were four bioprostheses. Anticoagulation was reversed in 12 patients and in all cases withheld for 15 (4) days. There were no thromboembolic complications. Over a six month follow up, 10 of the 19 patients remaining on warfarin had recurrent gastrointestinal (GI) bleeding. The authors conclude that the risk of thromboembolism is low in this setting and as rebleeding is common, the risk-benefit ratio of anticoagulation needs to be considered carefully.

8 Ananthasubramaniam K, Beattie JN, Rosman HS, Jayam V, Borzak S. How safely and for how long can warfarin therapy be withheld in prosthetic heart valve patients hospitalized with a major hemorrhage? Chest 2001;119:478-84.

\section{BASIC RESEARCH}

Upregulating anti-inflammatory mechanisms may reduce sepsis-induced myocardial depression: NFKB is a nuclear factor that regulates many inflammatory processes including
TNF- $\alpha$ production. $\mathrm{I}-\kappa \mathrm{B} \alpha$ is a potent inhibitor of this pathway, and transgenic mice with high production of this protein seem immune to the myocardial suppression seen normally in septic shock. It seems to work by blocking TNF- $\alpha$ production. TNF- $\alpha$ is recognised to be a myocardial suppressant, and anti-TNF therapy for heart failure of any cause is under investigation.

1 Haudek SB, Spencer E, Bryant DD, White DJ, Maass D, Horton JW, Chen ZJ, Giroir BP. Overexpression of cardiac I-B prevents endotoxin-induced myocardial dysfunction. Am J Physiol Heart Circ Physiol 2001;280: H962-8.

fournals scanned - American Journal of Medicine; American Journal of Physiology: Heart and Circulatory Physiology; Annals of Emergency Medicine; Annals of Thoracic Surgery; Annals of Internal Medicine; Archives of Internal Medicine; BMJ; Canadian Medical Association Journal; Chest; European Journal of Cardiothoracic Surgery; Lancet; JAMA; Journal of Clinical Investigation; Journal of Diabetes and its Complications; Journal of Immunology; Journal of Thoracic and Cardiovascular Surgery; Nature Medicine; New England Journal of Medicine; Pharmacoeconomics; Thorax.

Reviewers - C Baker, E Barnes, V Bhatia, R Desilva, M Earley, K Fox, D Gorog, G Jenkins, R Kaprilian, A Kapur, M Khan, P Lambiese, V Markides, M Poullis, P Ramrakha, J Strange, B Wasan, H Walker.

\section{Electronic pages}

\section{eHEART: www.heartjnl.com}

The following electronic only articles are published in conjunction with this issue of Heart.

\section{Trial to show the impact of nicorandil in angina (IONA): design, methodology, and management The IONA Study Group}

Objective-IONA (impact of nicorandil in angina) is a randomised, double blind, placebo controlled trial that will test the hypothesis that nicorandil (target dose of $20 \mathrm{mg}$ twice daily) will reduce the incidence of cardiovascular events in a cohort of men and women with effort angina and additional risk factors.

Methods - The primary composite end point of the study is coronary heart disease death, non-fatal myocardial infarction, or unplanned hospital admission for cardiac chest pain, and the secondary end point is the combined outcome of coronary heart disease death or non-fatal myocardial infarction. Other cardiovascular outcomes and all cause mortality will also be reported.

Results-More than 5000 subjects have been randomised to receive nicorandil or placebo in addition to normal antianginal treatment. The target population, the assessments made, and the management of the trial are described in detail.

Conclusions - The IONA study has achieved its first aim of randomising more than 5000 high risk subjects with effort angina. Subject follow up will be complete in the third quarter of 2001.

(Heart 2001;85:e9) www.heartjnl.com/cgi/content/full/85/ 6/e9

Ecstasy induced acute myocardial infarction A Qasim, $\mathcal{F}$ Townend, $M K$ Davies

A 23 year old man presented with a clinical history and ECG compatible with acute myocardial infarction, having taken a single tablet of ecstasy (3,4-methylenedioxymetamphetamine) 18 hours previously. $\mathrm{He}$ was treated with aspirin and thrombolytic therapy; however, cardiac catheterisation showed angiographically normal coronary arteries and left ventricular function. Sympathomimetic drugs are freely available and widely abused in Britain, but there is little evidence of the mechanisms or management of cardiac complications. In such cases the use of standard treatment for acute myocardial infarction is recommended with agents such as glyceryl trinitrate and phentolamine to reduce coronary artery spasm. Early coronary angiography may help to determine the relative contribution of spasm, thrombus, and underlying atherosclerotic disease.

(Heart 2001;85:e10) www.heartjnl.com/cgi/content/full/ $85 / 6 / \mathrm{e} 10$ 